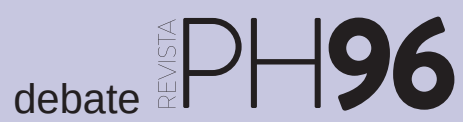

a debate Memoria democrática en la construcción de la historia y el patrimonio

| coordina Josefina Cuesta Bustillo

\title{
Memoria democrática en la construcción de la historia y el patrimonio
}

\author{
Dirección General de Memoria Democrática, Consejería de Presidencia, Administración Local y Memoria Democrática, Junta de \\ Andalucía ${ }^{1}$
}

URL de la contribución <www.iaph.es/revistaph/index.php/revistaph/article/view/4334>

Las políticas públicas de memoria impulsadas desde el gobierno andaluz se han desarrollado bajo la firme convicción de preservar e impulsar la memoria como un espacio público que crea espacios de convivencia y de respeto mutuo, a la vez que ayuda a asentar en nuestra tierra una verdadera cultura democrática fundamentada en los derechos humanos. Se trata de construir un relato común y compartido (que no uniforme) de la verdad acontecida; de recordar, reconocer y reparar a los que padecieron, por expresar sus ideas o murieron por defender los derechos de una sociedad libre como la que hoy disfrutamos; de cerrar definitivamente las heridas de las víctimas, reparando su sufrimiento y el dolor añadido por la falta de reconocimiento. De ahí la importancia de la Ley 2/2017, de 28 de marzo, de Memoria Histórica y Democrática de Andalucía, aprobada por el Parlamento andaluz sin votos en contra en esta legislatura y tiene como objetivo el de garantizar a la ciudadanía andaluza el derecho a conocer tanto la verdad de los hechos acaecidos como la protección, conservación y difusión de la memoria democrática como legado cultural de Andalucía.

La memoria es, ciertamente, de todos y todas, de los que tienen, por su formación, las herramientas para la construcción del relato, de los poderes públicos que tienen la obligación de activar políticas en las que recojan las demandas de la sociedad civil en materia de derechos humanos, y de la ciudadanía en general, sobre la que un relato verídico, objetivo y asumible por todos y todas, tiene efectos beneficiosos, por cuanto supone conocimiento para la divulgación y la pedagogía, pero también para la asimilación y la concienciación para la no-repetición de la barbarie. Se trata, por tanto, de una tarea compartida basada en la corresponsabilidad de todos los actores que actúan para la recuperación de la memoria histórica pero donde los poderes públicos deben estar en vanguardia fijando siempre la mirada en la doble utilidad de la memoria: como forma de reparar el agravio y como herramienta para construir un futuro mejor.

Es totalmente necesario patrimonializar la memoria democrática, y puede (y se hace) de muchas formas, desde las intervenciones encaminadas a la localización y recuperación de las víctimas en las fosas comunes, al señalamiento de los espacios emblemáticos vinculados a este periodo (lugares de memoria histórica y democrática) o a la monumentalización de los otrora espacios de oprobio e ignominia; desde la colaboración entre administraciones, entidades y asociaciones; desde la investigación y el conocimiento, la divulgación y la pedagogía. Y todo ello para cumplir con los principios de Verdad, Justicia, Reparación y garantía de No-Repetición.

¿Recuperar y poner en valor una memoria no implica el olvido de otras? Jamás si se hace bien, porque no existe además "una memoria", o no debiera existir al menos. Debe, en cambio, existir "la memoria", en el sentido del relato que se identifique y asuma colectivamente. Hay que hacerlo con rigor y desde el principio de cooperación, entendiendo la memoria como un proceso de recuperación de las historias de quienes fueron olvidados y sobre cuyas vidas o bien nunca se habló o bien sus relatos se tergiversaron por el régimen. La memoria es una mezcla de las experiencias vividas, de sentimientos y, sobre todo, de una enorme generosidad, es una voz que recuperamos para ayudarnos a mirar y entender nuestro pasado trágico de una manera crítica. Y, sí, tiene mucho de subjetivo pero una subjetividad que proviene del dolor y del padecimiento de miles de inocentes. 
a debate Memoria democrática en la construcción de la historia y el patrimonio

| coordina Josefina Cuesta Bustillo

No creemos en las verdades enfrentadas, sí contrapuestas, fruto del análisis del pasado que hacemos desde el presente. Esa contraposición no debe ser negativa sino todo lo contrario, un motor y una excelente herramienta para seguir dialogando, investigando, reparando el daño de todos los que sufrieron una violencia injustificada, por tanto, para resolver esa dicotomía quizás sea clave la profundización en la Verdad como es la única forma útil de cerrar las heridas del pasado.

Una cosa es la memoria y otra la historia, ambas son complementarias pero la historia profundiza en los hechos desde el análisis de procesos complejos desde una mirada más general. La memoria, en cambio, radica en el protagonista que aporta una mirada llena de texturas que enriquecen el análisis histórico y que se fundamenta en el padecimiento, el olvido, los silencios y la lucha contra la invisibilidad. La historia siempre está en riesgo de ser manipulada para lo cual es imprescindible, y volvemos a insistir, profundizar en la investigación rigurosa y en el conocimiento de la Verdad. Abordar el pasado, al igual que los requerimientos del presente, desde la seriedad y el rigor, sin trincheras políticas, solo atendiendo a lo que dicen las víctimas y establecen los organismos internacionales en materia de derechos humanos.

¿Retiramos de nuestros espacios públicos símbolos asociados a totalitarismos o preservamos con valor pedagógico? Ambas cosas son compatibles en determinados supuestos. En cualquier caso, se prohíbe la exhibición pública de aquellos elementos que enaltezcan el golpe militar y la dictadura franquista, que son contrarios a la propia dignidad de las víctimas o constituyen una exaltación del enfrentamiento.

Es, por tanto, retirar del espacio público esos elementos $y$, en otros casos, mantener y explicar por qué es un símbolo que constituye una ofensa contra las víctimas con arreglo a nuestras leyes de memoria. No hay una sola receta ni se puede hacer tabla rasa con todo, y por ello se encuentra actualmente en última fase de tramitación un decreto que regula un comité técnico compuesto por personas expertas que tendrá la última palabra en este tema.
Llevar a cabo la labor de difusión e interpretación de la memoria democrática sin que suponga una banalización de la historia se consigue desde el rigor, con escrupulosidad histórica, y con una selección "cuidada" de espacios de especial significación que representen el conocimiento de los hechos y el recuerdo a las víctimas, pero evitando que una proliferación exagerada provoque una pérdida de fuerza de mensaje y simbolismo, que se termine incurriendo en esa banalización a la que se refiere.

En relación con la puesta en valor de la memoria democrática desde una perspectiva de género, Andalucía es también un ejemplo en el tratamiento que desde las políticas públicas de memoria se ha otorgado de manera específica a la mujer, y desde varios ámbitos: tanto desde la aprobación de normativa que recoge indemnizaciones específicas a mujeres vejadas y ultrajadas como consecuencia de la represión franquista, como desde la investigación y divulgación (subvenciones en las que se ha valorado la perspectiva de género de los proyectos, documentales en las que el protagonismo era ostentado por mujeres), o intervenciones específicas en "fosas de mujeres" (las "17 rosas" de Guillena, las mujeres de Grazalema, las "niñas" de El Aguaucho, o la fosa de las mujeres de Higuera de la Sierra).

Nuestro compromiso e implicación con la cuestión de género es total, y así se confirma en el recientemente aprobado por Consejo de Gobierno I Plan Andaluz de Memoria Democrática, en el que se recoge, entre las líneas de actuación que deben regir este plan plurianual, las destinadas a este ámbito.

\section{NOTAS}

1. Contribución que llegó a revista $P H$ el 13 de diciembre de 2018. Con el Decreto 2/2019 de 21 de enero las competencias de memoria democrática pasan a corresponder a la Consejería de Cultura y Patrimonio Histórico de la Junta de Andalucía. 